\title{
Palhaças mulheres e mulheres palhaço: o travestismo na palhaçaria
}

\section{MELISSA LIMA CAMINHA \\ JUDIT VIDIELLA PAGÈS}

\section{Resumo}

A palhaça é uma figura recente na história das Artes

Cênicas e vem ganhando espaço e visibilidade através de um movimento articulado, entre outros fatores, em torno de uma categoria denominada "comicidade feminina". Nesse contexto de reivindicação e visibilização da comicidade da palhaça, emergem diversas problemáticas relacionadas ao gênero na palhaçaria. Este artigo aborda um desses problemas: o travestismo das mulheres nessa prática artística. A partir de um enfoque feminista-queer, elaboramos algumas perguntas sobre a performance das mulheres na palhaçaria, que possam ampliar o debate sobre a categoria de "comicidade feminina" elaborado por diversas palhaças nos últimos anos.

Palavras-chave:

Palhaçaria, comicidade feminina, travestismo 


\section{Women's Transvestism in Clownery}

\section{MELISSA LIMA CAMINHA \\ JUDIT VIDIELLA PAGĖS}

\section{Abstract}

The female clown is a recent figure in the history of the performing arts, and has gained space and visibility through a movement articulated around a category called "feminine comicality." In this context of vindication and visibility of women's clown comedy, emerges several gender problems of this artistic community. This article addresses one of these problems: the transvestism of women in clownery. From a feminist-queer perspective, we have elaborated some questions about the performance of women in clownery, Keywords: which can broaden the debate on the category of "feminine comicality" developed by women clowns in the last years. 


\section{Payasas Mujeres y Mujeres Payaso: el travestismo en la payasaria}

\section{MELISSA LIMA CAMINHA \\ JUDIT VIDIELLA PAGÈS}

\section{Resumen}

La payasa es una figura reciente en la historia de las Artes Escénicas y viene ganando espacio y visibilidad a través de un movimiento articulado, entre otros factores, en torno de una categoría denominada "comicidad femenina". En este contexto de reivindicación y visibilización de la comicidad de la payasa, emergen diversas problemáticas relacionadas al género en la payasaria. Este artículo aborda uno de estos problemas: el travestismo de las mujeres en esta práctica artística. Desde un enfoque feminista-queer, elaboramos algunas preguntas sobre la performance de las mujeres en la payasaria, que puedan ampliar el debate sobre la "comicidade feminina" elaborada en los últimos anos.

Palabras clave:

Payasaria, comicidad femenina, travestismo 


\section{Mujeres, payasaria y la "comicidad femenina"}

Mientras la intervención feminista en la Historia del Arte empieza a tomar cuerpo solido en las décadas de los 60 y 70,

el surgimiento y la profesionalización de la payasa mujer solo vendrían a efectuarse a partir de los 8o. Payasas como Annie Fratelinni (Francia), Gardi Hutter (Suiza), Nola Rae (Australia e Inglaterra), Pepa Plana y Virgínia Imaz (Cataluña y País Basco/España), Angela de Castro y Ana Luísa Cardoso (Brasil), Laura Herts y Hillary Chaplain (EUA), Francine Côté (Canadá), son algunas de las mujeres que empezaron a profesionalizarse como payasas en el ámbito del teatro y del circo.

Pero es con el Festival de Pallasses de Andorra, realizado por primera vez en 2011, que se marca el inicio de una conciencia colectiva de la mujer en el ámbito de la payasaria. Iniciando un proceso de diferenciación de lo que sería una comicidad masculina, las mujeres payasas empiezan a construirse como sujetas rientes y risibles, reivindicando un espacio cómico históricamente dominado por los hombres: la payasaria.

Después del festival en Andorra, payasas de varios países han dado continuidad al circuito de festivales y encuentros de payasas, promoviendo y fomentando la payasaria de las mujeres, bien como investigaciones y debates sobre lo que se viene conceptualizando como "comicidad femenina". Mientras que categorías como las de unruly woman y woman on top (ROWE, 1995; DAVIS, 1978) - fundamentales para la comprensión teórica e histórica de la mujer cómica - han sido trabajadas dentro de un contexto teórico feminista, la última es fruto del actual movimiento de payasas mujeres, pues la payasa surge en el ámbito del teatro y del circo, pero se mantiene un tanto aislada del arte y teoría feminista. Por otro lado, den- 
tro de la teoría feminista también parece haber un desconocimiento, indiferencia y/o prejuicio existente sobre la figura de la payasa, ya que el feminismo siempre ha hecho referencia a la risa, la parodia y lo grotesco como herramientas conceptuales y estrategias de resistencia. Y aunque en los últimos años las payasas parecen venir apropiándose cada vez más del discurso y prácticas feministas, creemos que se hace necesario tejer hijos de colaboración más sólidos entre teoría feminista y prácticas de payasaria.

Elaine Nascimento (2014) considera la "comicidad femenina" como comicidad producida por payasas mujeres, como parte de un movimiento que busca visibilizar la mujer en la payasaria, diferenciándose, por tanto, del canon cómico masculino. Además del foco en la producción de payasaria hecha por mujeres, esta "comicidad femenina" tematiza y problematiza el "universo femenino". Nascimento no considera que haya una distinción de principios y técnicas cómicas diferenciadas de una teoría de la comicidad, sino que hay una especificidad en los sujetos cómicos, bien como en el material y construcción de las performances.

A pesar de indagar brevemente sobre el travestismo, y de la posibilidad de que esta comicidad femenina pueda ser ejecutada también por hombres, Nascimento la concibe como una categoría estrechamente relacionada al movimiento de mujeres payasas que se ha desarrollado en los últimos años. O sea, la autora no se preocupa tanto en problematizar la categoría en sí, sino que identificar cuándo, cómo y porque ha surgido. O sea, la comicidad femenina es una categoría reciente, que se desarrolló por payasas mujeres para identificar políticamente a un colectivo artístico, que, en su momento histórico, sintió la necesidad de diferenciarse de una comicidad masculina en el ámbito de la payasaria.

Mariana Junqueira (2012) sigue la misma línea de Nascimento, explicando y describiendo la comicidad femenina como comicidad de mujeres payasas. Junqueira también pone acento en el sujeto de comicidad: las mujeres. También llega a elaborar una taxonomía de payasas, proponiendo los siguientes tipos: la moleca, la mujer más fuerte del mundo, la blanca, la augusta y la travestida. La autora explica brevemente cómo sería cada una de estas tipologías, con base en ejemplos de payasas que ella ha conocido. La taxonomía propuesta está muy basada en su relación con el "universo femenino" y su opuesto: la "comicidad masculina". La payasa blanca y la augusta, por ejemplo, tratan de repetir las nomenclaturas "pa- 
yaso cara blanca” y "payaso augusto", establecidas por el circo moderno. La "payasa más fuerte del mundo" es aquella que busca contestar el imaginario de la mujer como sexo frágil. Ya los tipos "la moleca" y "la travestida" no problematizan, pero invitan a una mirada crítica que vaya más allá de las categorías de género.

Moleca, en Brasil, remete a la idea de una adolescente o mujer con maneras de niña, de niña traviesa, una mezcla de malicia y dulzura. Sin embargo, el ejemplo que Junqueira sugiere de payasa moleca es la payasa Jasmin - performer Lily Curcio - , en su actuación en el número Inocêncio. En este número, Lily trabaja un personaje que juega con la mezcla femenino y masculino. El número consiste, básicamente, de la entrada de Lily como un hombre campesino. Él quiere hacer pipi y abre los pantalones para sacar el pito y mear en una cuenca. Sin embargo, al abrir el pantalón, no es un pene que le sale, sino que la tromba de un elefante. Lily mea leche en una cuenca, con la cual alimenta su mascota.

Junqueira apunta el número de Lily como ejemplo de payasa moleca, resaltando la performance de Lily como un número en que la payasa va más allá de la dicotomía de género, libertándose así de referencias binarias como lo masculino y lo femenino": "Jasmim é um moleque, um menino de rua, e ao mesmo tempo, a mais doce das meninas que já vi. Ao carregar os dois gêneros em seu estado infantil, ela se liberta das diferenciações e se permite construir sua comicidade para além dessas referências."2 (JUNQUEIRA, 2012, p. 59).

La tipología travestida, por su vez, se refiere a las payasas que se travisten de hombre o tienen un tipo masculino. Aquí las referencias son las brasileñas Angela de Castro e Yeda Dantas, y sus tipos masculinos: payasos O Souza y Dr. Giramundo, respectivamente. Aquí el travestismo en la payasaria tampoco es problematizado, sino que descrito como una tipología más a componer una especie de taxonomía de payasos y payasas. Mariana llega a comparar el travestismo de payasas con el travestismo de payasos, pero sugiere que el primero es un contrapunto similar a la performance de payasos que se travisten de mujer. La autora cita a payasos como Ricardo Puccetti y Simioni - Teotonio y Carolino, del grupo brasileño LUME - que, en su espectáculo Cravo Lírio e Rosa, se travisten de mujer. Tanto los payasos brasileños, como payasos famosos como Jango Edwards y Charlie Rivel, no solo juegan con el cambio de roles de género, sino que presentan características, elementos y sensibilidad consideradas femeninas. 
Annie Fratellini (1999), por su vez, en su libro Destin de Clown, no se define como mujer payasa. Para ella, el clown es asexuado, es neutro, de forma que el clown es tomado como tipo cómico que se sitúa más allá de las dicotomías de sexo y género. Esta concepción de que el clown es asexuado o neutro es muy problemática, porque, como nos recuerda Susan Horowitz, "Among many anthologies and studies of comedians, women are significantly missing or minimized. The norm is not neutral. It is male"3 (HOROWITZ, 2005, p. ix).

De forma general, el travestismo en la payasaria ha sido explicado así:

- Como estrategia de sustitución de payasos en el circo, cuando el payaso hombre está enfermo o ausente. Esta es, incluso, la principal explicación para el surgimiento histórico de la payasa en el circo moderno.

- Como herencia de una payasaria que históricamente solo ha aportado referencias masculinas.

- No es una cuestión de travestismo, sino de una supuesta neutralidad y/o asexualidad atribuida a la figura del payaso.

- Como contrapunto natural y/o similar de un fenómeno análogo: el travestismo de payasos hombres.

Estas explicaciones no llevan en cuenta la complejidad social y cultural inherente

a las prácticas del travestismo, bien como la importancia de estas prácticas en la formación de la subjetividad de la artista y de la identidad clown. Así que, en los próximos apartados, tratamos de analizar el travestismo de las mujeres en la payasaria a partir de un abordaje feminista y queer.

\section{Ensayo para la disolución de la feminidad y masculinidad heteronormativas.}

Muitas mulheres, quando começam a buscar seu palhaço, deparam-se com um tipo masculino. Coisa muito normal e facilmente explicada num mundo ainda tão dominado pelos homens e onde as referências masculinas são tão abundantes e fortes [...]. Ao buscar sua persona cômica é grande a chance de uma mulher ver surgir forte um ser masculino, e o fato de aceitá-lo e desenvolvê-lo é uma decisão pessoal, íntima e para a qual não cabe crítica nem tentativa de interpretação ou julgamentoiv (CASTRO, 2005, p. 222). 
Alice Viveiros de Castro (2005), al tratar de la comicidad de las mujeres, apunta para lo que sería la emergencia de dos tipologías en la payasaria: las "payasas mujeres" y las "mujeres payaso". La autora no llega a desarrollar un análisis de estas tipologías, pero tales tipos sugieren algunas interpretaciones interesantes relacionadas al género y la sexualidad en la comicidad.

La expresión mujeres payaso, por ejemplo, puede hacer referencia a mujeres que, a pesar de nombrarse como heterosexuales, desarrollan un tipo cómico masculino. Lo hacen, probablemente, debido a la ausencia de modelos femeninos en el ámbito de la payasaria, al peso y fuerza del patriarcado en esta práctica artística. La expresión también podría indicar una parte del colectivo de mujeres lesbianas, que no encuentran ningún problema ni dificultad al construir sus personas cómicas como un tipo masculino. La categoría de "masculinidad femenina”, elaborada por Judith Halberstam (1998), nos puede ayudar a comprender como estas mujeres se han construido como mujeres payaso, en una comprensión que vaya más allá de la relación biológica que se estableció como natural entre mujer y feminidad. Es decir, así como los hombres también han producido feminidades, las mujeres también hemos producido masculinidades, desde nuestras performances cotidianas y artísticas.

Ya la expresión payasas mujeres parece estar más vinculada a las artistas que asumen una condición femenina y exploran la comicidad desde tal condición, como forma de contestar un imaginario machista y patriarcal relacionado al "mundo payaso", y de visibilizar la mujer en su oficio de payasa con "A".

Esta sugerencia de tipologías es interesante porque invita a una mirada amplia sobre la diversidad de cuerpos y formas cómicas que las mujeres pueden traer en la construcción de sus personajes, performances y discursos. Cuerpos y formas que traducen estéticas, estilos, deseos, afectos y performances diversas relacionadas a la identidad de género y sexualidad del artista y/o personaje.

Por otro lado, sin embargo, las tipologías payasas mujeres y mujeres payaso también pueden sugerir un modelo binario basado en el sistema heteronormativo, es decir, un sistema que disciplina y normatiza género y sexualidad, siguiendo la falsa continuidad existente entre sexo y género, biología y cultura, natural y artificial. Un sistema heteronormativo que instituye 
como norma la heterosexualidad compulsoria - tal como ha sido trabajada por Rich (1980) y Wittig $(1992,2006)$-y las categorías hegemónicas de masculino y femenino disciplinadas e instituidas por este modelo.

De hecho, la categoría femenina ha sido y continúa siendo de uso común entre muchas mujeres para especificar y diferenciar su oficio de payasa. Muchos de los encuentros y festivales de payasas utilizan el término femenina en su título, como, por ejemplo, el Festival de Comicidade Femenina - Esse Monte de Mulher Palhaça, en Rio de Janeiro. Este, siguiendo su antecesor festival de Andorra, así como otros eventos, cursos e investigaciones utilizan la expresión "humor femenino", "palhaçaria femenina" o "fórum de la comicidad femenina", para hacer referencia a la payasa como tipo cómico.

Es cierto que el establecimiento de la categoría de comicidad femenina tuvo mucha fuerza política en un primer momento, pues sirvió para reivindicar el oficio de la payasa y contra producir una comicidad lejos del modelo hegemónico de masculinidad de payasos del circo y del teatro. Sin embargo, esta categoría acaba limitando los cuerpos, formas y discursos cómicos de mujeres que no se identifican con la idea de feminidad.

Este tema es evidente si abordamos la payasaria desde un enfoque feminista- queer sobre la construcción de la identidad de género, del deseo y la sexualidad. Lo femenino y la feminidad han sido y continúan siendo categorías criticadas por inúmeras mujeres y feministas que encuentran en ello una de las principales categorías culturales que las mujeres deben problematizar en la lucha por la libertad e igualdad, en la lucha por la desestabilización de normas naturalizadoras que restringen la sexualidad, el deseo y la vida misma.

Aunque aquellos eventos sean ambientes abiertos a la diversidad y no tengan la intención de discriminar, excluir o limitar la participación de ninguna mujer, creemos que la categoría comicidad femenina no es la adecuada para un arte que se propone subversiva y contestadora como es el arte de la payasa. El festival de payasas de Viena, quizás, haya acertado más en este sentido. En lugar de inscribir la feminidad en su título, sus organizadoras han preferido adoptar la denominación Clownin - International Women's Clown Festival. Y aunque la categoría de mujer también es problemática, el plural usado en el sustantivo sugiere una posibilidad de abertura a la indagación sobre la construcción del género.

Aún en relación a los festivales, encuentros y fórums de comicidad femenina, habría que pensar sobre la abertura o no 
a la participación de hombres que también trabajan con una "comicidad femenina". Si tomamos el género como construido y lo masculino y lo femenino como cualidades performativas no vinculantes al sexo anatómico de lxs sujetxs, habría que pensar en las posibilidades de que en estos festivales se pudiera presentar performances, por ejemplo, de drag queens, ya que éstas trabajan la comicidad desde lo femenino. En este caso, estamos no solo repensando la construcción de la feminidad en la diversidad de cuerpos existentes, sino que rescatando formas cómicas que no encajan en el arquetipo universal de la comicidad, traducidos muchas veces en una estética i poética de la payasaria.

También habría que indagar como la participación de mujeres payasos negocian la comicidad masculina de sus personajes con el imperativo de la comicidad femenina que se afirma en los festivales. La misma reflexión cabe para las payasas mujeres que también exploran trazos y manierismos masculinos en sus performances.

Entre los varios personajes creados por la payasa Nola Rae, por ejemplo, tenemos sus famosas versiones de Mozart y Napoleón. La payasa y mímica australiana- inglesa también tiene un número de clown bellísimo, en el cual se presenta en traje de bufón medieval y bobo de corte, un visual más bien asociado con la bufonería tradicional, o sea, male buffon. Nola también parece adoptar un visual ligeramente andrógino al ejecutar un lindo número de mimo y ballet clásico - Nola's Nasty Mime - , por lo cual deconstruye el género de forma increíble. Otro ejemplo interesante es el grupo australiano The Business, formado por cuatro mujeres clown que dan vida a cuatro personajes masculinos: Glynis Angel es Ray, Kate Kantor es Paul, Penny Baron es Barry y Clare Bartolomew es Pierre. La brasileña Paloma Fraga, por su vez, construye su payasx Android completamente basada en una crítica al sistema heteronormativo:

Android surge primeiramente da necessidade de discutir a questão de gênero dentro da esfera de atuação de palhaçxs no Brasil. Festivais, mostras, encontros e até grupos de palhaçxs vem criando por vezes um movimento separatista entre homens e mulheres, para empoderar a mulher frente à sociedade patriarcal na qual vivemos. Os homens, muitas vezes nas rodas de palhaçx, usam a máscara para reafirmar sua cultura machista. Na maioria dos casos, eles nem se dão conta, pois mesmos pequenos gestos, ou simples discursos, já estão nor- 
matizados, e se tornam comportamentos comuns dentro das relações. Isso legitima a frente feminista, e torna necessária a discussão. Porém, a cultura machista também atua de maneira opressora sobre os homens. Neste caso, a discussão se amplia, sendo urgente olhar para ela pela lente do humano, onde natureza (sexo) e cultura (gênero) não são realidades separadas. [...] Androide deseja estar no entre, onde as possibilidades são plurais, propondo um ambiente onde não haja hierarquias nem entre sexo, nem entre sujeitos culturaisv (FRAGA, 2015).

Tal como nos explica Karla Concá - payasa Indiana (grupo As Marias da Graça: organizador del festival) -, la idea del festival de Rio de Janeiro es "cerrar para luego abrir", o sea, reservar un espacio cerrado dónde las mujeres se sientan cómodas, seguras y con confianza entre sí, para después abrirse a los circuitos culturales dichos "mixtos". Este enfoque en la reunión de mujeres como política que refuerza la solidaridad, intimidad y confianza en las artistas, es resaltado por diversas payasas, y es una mola maestra de las políticas feministas.

De forma que estos festivales parecen no solo querer afirmar lo femenino de la payasaria de mujeres, sino también construir encuentros, contactos, espacios de convivencia en los cuáles las mujeres puedan desarrollarse artística y afectivamente, bien cómo organizar-se políticamente, apoyándose unas a las otras y generando una red de contactos y colaboraciones entre mujeres que, unidas, luchan por un espacio de visibilidad en la sociedad y el sector cultural. O sea, el "femenino" de la "comicidad femenina" del movimiento de payasas se refiere más bien a la categoría "mujer" que a un supuesto elemento natural y biológico femenino, que excluye lo masculino en la performance de mujeres payasas. De todas formas, aún queda en abierto poner en la agenda del movimiento de payasas - y su categoría de comicidad femenina - , una reflexión sobre la consideración y abertura, por ejemplo, de las performances de sujetxs trans y queer que se consideran mujeres y/o femeninas.

En el ámbito de la teorización sobre el tema de la feminidad en la payasaria, cabe aún señalar el texto de Franca Rame. La payasa italiana sea quizá una de las primeras mujeres a escribir sobre la payasa, pero su posición es bastante radical cuando el tema es el travestismo de mujeres clown. Según esta autora, la mujer tiene casi una obligación de explorar un papel femenino. Rame levanta severas críticas a las mujeres que componen su persona cómica como un tipo masculino. El 
resultado de ese personaje "mujer-payaso", según la autora, es un "un híbrido terrível, um beco sem saída"vi (RAME, 2004, p. 345) Y citando el caso de una actriz que hacía perfectamente el rol de un clown, añade:"Se tivesse nascido homem seria um clown inigualável. Infelizmente, porém, não quis ou não conseguiu encontrar um papel cômico totalmente feminino. Assim, precisou abandonar, não só o papel do palhaço, mas o próprio ofício tout court"7 (RAME, 2004, p. 345). La autora radicaliza la necesidad de expresión femenina en la creación de la persona cómica de las mujeres. Y criticando duramente la tendencia "asexuada" de maestros del mimo como Marcel Marceau, concluye:

Algo pior que isso, só quando uma mulher representa um desses pierrots. Um homem sem sexo ainda é aceitável, mas uma mulher sem sexo, nunca. [...]. Uma atriz deve interpretar papéis femininos. Um ator é capaz de fazer admiravelmente o papel do travestido, podendo encontrar, através do sentido caricaturesco, modulações bastante agradáveis. Uma mulher "transvestida” não tem o menor significado, a não ser que, no contexto da ficção cênica, não seja um travestismo explícito, expresso de maneira evidente e cristalina. Aliás, declaradamente: não deve haver qualquer dúvida de que o personagem está executando um jogo. Esse transvestismento patente era um dos recursos espetaculosos mais usados na Commedia dell'Arte. E só funcionava porque a atriz, por meio de seu fascínio, de suas formas (particularmente, pela protuberância arredondada dos seus seios) e, principalmente, por sua elegância e graça, já havia provado ao público sua condição feminina. Então, e só então, a atriz podia se permitir o transvestismentoviii (RAME, 2004, pp. 345-346).

La autora apuesta por una comicidad femenina como única posibilidad de éxito para las performances de las payasas. Este posicionamiento refleja un fuerte esencialismo patriarcal, porque no considera que haya espacio para una risa de la "masculinidad femenina" (HALBERSTAM, 1998). Para Rame, la estrategia drag, cuando utilizada por la mujer, solo despierta risa cuando al mismo tiempo se trabaja desde la exposición de los rasgos de hiperfeminidad, tales como la marca de los senos. De forma que la mujer travestida de hombre no despierta risa porque lo masculino es tomado como "neutral", que, por su falsa cualidad "natural" no puede ser ridiculizada y no hace gracia. 
La obstinada afirmación de Rame en relación al travestismo de mujeres merece una reflexión más cuidadosa, si no queremos mantener un discurso y una práctica exclusiva de una comicidad hegemónica, payasil, ahistórica y universal. En su afirmación, la autora reconoce y legitima el travestismo del hombre, pero limita y desalienta el travestismo de la mujer. Rame no reconoce el potencial risible de la "masculinidad femenina". Su visión de la mujer es extremamente limitada a una concepción de una feminidad monolítica, entendida como destino biológico del sexo anatómico.

Si la payasaria de las mujeres tuviera la obligación de probar su condición femenina, eso presupondría una condición biológica, de una feminidad determinada por el sexo anatómico, de una identidad de Mujer transhistórica y universal, de una Mujer sin las debidas diferenciaciones étnicas, geográficas, socio-culturales, económicas y sexuales, de una Mujer que se presenta como esencia, origen, y materia pre-discursiva. Sin la debida atención a una comicidad histórica, cultural y localizada, el discurso de las payasas se encuentra imprimido en una reglamentación heterosexual tan severa como la impuesta por la comicidad patriarcal, que legitima, valoriza y visibiliza solamente una pequeña parte del mundo cómico, la una de los payasos, y más recientemente, también de las payasas y su movimiento articulado en torno de una comicidad femenina.

Tal y como ha pasado con la intervención feminista en la Historia del Arte, cuando mujeres como Griselda Pollock (1988) y Linda Nochlin (1971) se preguntaban si el arte feminista proponía una especie de esencialismo o estilo particular de las mujeres, también habría que preguntar si la payasaria de las mujeres, al deconstruir el canón machista y patriarcal del circo y de la payasaria, a veces también no cae en la trampa del determinismo biológico.

\section{El travestismo de la mujer en las Artes Escéni- cas y la Performance}

Como observamos en los trabajos de diversas historiadoras del Teatro y la Performance (CASE, 1988; BERTHOLD, 2001; GAY, 2002; HART y PHELAN, 1983), la historia oficial del teatro es una historia de invisibilidad y prohibición de la performance escénica de las mujeres. La historia visibiliza un teatro oficial que se da en los teatros burgueses, en detrimento de un teatro popular y callejero. Y es que, históricamente, desde 
Grecia hasta el Teatro Isabelino, no se les han dado mucho permiso a las mujeres para actuar, salvo en aquellos contextos no oficiales, populares, callejeros y de feria, en los cuales muchas mujeres llegaron a actuar, pero han sido olvidadas o silenciadas, ya que la historia del teatro fue, por mucho tiempo, una historia de la dramaturgia y del teatro oficial, con pocas referencias a una historia del teatro físico y la actuación.

El Teatro Griego es un marco en la historia del teatro occidental, en lo que ello describe y organiza la estructura, las normas y las convenciones del teatro tradicional. Prueba de ello es que la obra Poética, de Aristóteles (1999), sigue hasta hoy siendo referencia fundacional del teatro occidental en los estudios teatrales. En ella, Aristóteles deja claro la misoginia de la sociedad ateniense de la época, en que la mujer ha sido prohibida de ocupar el espacio público, siendo destinada solamente a la ejecución de las labores y funciones domésticas, reproductivas, maternales y sexuales. Las mujeres eran equiparadas a los esclavos, y así como pasaba a ellos, se les era atribuido falta de inteligencia y capacidad de oratoria para tratar de temas públicos de la polis (CASE, 1988).

Posteriormente, la cultura cristiana ha localizado la sexualidad misma en el cuerpo de la mujer, haciendo con que su exposición pública fuera un peligro para la moralidad de la época. La mujer fue asociada con la sexualidad y la amenaza a la moralidad. El hombre era el único que tenía derecho a ocupar el espacio público, y así también, el escenario. Mientras la mujer simbolizaba lo carnal, lo sexual, lo inmoral, el hombre simbolizaba lo espiritual, lo abstracto, lo moral. De ahí la relación de la mujer actriz con la prostituta. El simple hecho de actuar en público ya configuraba la exposición del cuerpo sexualizado, y por lo tanto, una invitación o tentación al pecado. Las mujeres fueron prohibidas de actuar en el teatro, y el Teatro Isabelino sigue con la práctica del travestismo como única forma de darles vida a los personajes femeninos.

Por tanto, desde Grecia hasta el Teatro Isabelino, los papeles femeninos han sido interpretados por hombres travestidos de mujer. El permiso para el travestismo de hombre para mujer (Male to female-MTF) ha sido históricamente más frecuenteque el travestismo de mujer para hombre (Female to male - FTM).

Fuera del contexto teatral, el travestismo de las mujeres parece haber encontrado más espacio para darse, por razones más diversas. Sea como disfraz para protegerse de la violencia pública, sea como disfraz para luchar en disturbios y guerras, sea para que las mujeres pudiesen ocupar cargos y funciones 
públicas a ellas prohibidas, sea como estrategia entre parejas de lesbianas para engañar a la sociedad - como código de supervivencia butch, o sea, como mímesis o passing social de FTM (HALBERSTAM, 1998).

Podemos citar algunos personajes y leyendas históricas conocidas, tales como: la leyenda de la Papisa Juana, que engaña a la Iglesia para convertirse en el primer pontífice mujer. Juana de Arco quien se convirtió en líder del ejército francés en la guerra de los Cien Años y luego fue perseguida y condenada por la herejía de travestirse de hombre. Catalina de Euraso, española, más conocida como Monja Alférez, se disfrazó de hombre para escapar de un convento y luchar como soldado en América. La mexicana Sor Juana Inés de la Cruz, que se disfrazó de hombre para estudiar en la universidad cuando aún no se aceptaban mujeres, entre otras.

Ya en el ámbito de la inversión sexual simbólica, se hace oportuno comentar la obra de Natalie Zemon Davis (1978), en la cual apunta ejemplos de inversión sexual en imágenes, en la literatura y en diversas festividades populares a principio de la era moderna en Europa. El curioso que se demuestra a través de su investigación, es que la imagen de la mujer travistiéndose de hombre fuera más común tanto en la creación de imágenes en las artes visuales como en la creación literaria. Pero en el ámbito de las festividades populares, en las cuales esta inversión se daba de forma corporal y performática, la gran mayoría de ejemplos conocidos o registrados son de hombres travistiéndose de mujeres.

Whereas the purely ritual and/or magical element in sexual inversion was present in literature to only a small degree, it assumed more importance in the popular festivities, along with the carnivalesque functions of mocking and unmasking the truth. Whereas sexual inversion in literary and pictorial play more often involved the female taking on the male role or dressing as a man, the festive inversion more often involved the male taking on the role or garb of the woman - that is - of the unruly woman - tough this asymmetry may not have existed several centuries earlier (DAVIS, 1978, p.163-164)..

John Towsen (1976), por su vez, realiza una extensa investigación sobre diversas tipologías liminales relacionadas a la genealogía de los payasos, dando diversos ejemplos de cómo los clowns se han construido como arquetipos de comicidad que instauran el "mundo al revés", muchas veces, a través del 
juego con la inversión sexual simbólica. En su obra, no hay prácticamente ninguna referencia sobre la mujer en todas las épocas y formas culturales de comicidad y risa presentadas.

Ya en el primer capítulo, dedicado a lo que el autor llama Fools, natural and artificial, Towsen trata de ejemplificar formas y rituales de diversas tribus y sociedades que contienen la figura del clown como una de sus principales expresiones culturales de libertad, libertinaje y risa. Y todos los ejemplos señalados en la obra tratan de performers hombres. Incluso cuando las festividades traen en su nombre referencia a la mujer, son a los hombres que toca representarlas, a través del travestismo simbólico. Encontramos un ejemplo de estas festividades en la Francia medieval de los siglos XV y XVI, a través de las sociétés joyeuses. Eran sociedades amadoras cuyos miembros se dedicaban a organizar fiestas populares basadas en la folía, la diversión, la parodia y la inversión de papeles sociales. Entre las diversas festividades promovidas por estas asociaciones, estaba la famosa Feast of Fools - abolida por la Iglesia en el año 1500; y la Mère-Folle, que a pesar de llevar consigo el nombre "madre", "the role was rarely if ever filled by a woman" ${ }^{10}$ (TOWSEN, 1976, p. 20).

La inversión sexual simbólica como performance presente en las diversas expresiones culturales es uno de los principales juegos en las artes visuales, literatura, rituales y festividades. Expresiones y manifestaciones culturales que se proponen poner el mundo al revés, romper con estructuras jerárquicas oficiales e instaurar una especie de estado cómico temporario de experimentación de una nueva sociedad. Esta experimentación con la inversión sexual, sin embargo, parece haber sido y continuar siendo un permiso concedido por hombres y para hombres. Lo que podemos inferir de estas manifestaciones populares, es que los hombres siempre tuvieron permiso para travestirse de mujeres, pero el permiso contrario no se daba con frecuencia, o al menos el travestismo de la mujer no ha sido registrado como actos de comicidad, irreverencia, parodia, crítica social, expresión ritual o festiva.

Case (1988) explica que la deconstrucción feminista de la historia del teatro ha fallado por limitar su atención al análisis de los textos clásicos. Según la autora, la crítica feminista se olvidó de interrogar sobre la ausencia de la performance de la mujer, y sobre un escenario dominado por los hombres: "the all-male stage". De acuerdo con ella, las prácticas de travestismo comunes para representar los roles femeninos pueden ser consideradas misóginas pues acaban celebrando el homoero- 
tismo de chicos en drag, a través de la representación sexualizada de la mujer.

La autora sugiere que la tradición crítica del patriarcado, al estetizar el travestismo masculino en el escenario, obedece a los mismos principios que la Iglesia católica ha usado para excluir a las mujeres. O sea, que el género masculino en celibato es el lugar apropiado para la performance pública y la producción artística. Según la autora, la estética acaba sustituyendo la espiritualidad:

Aesthetics merely replaces spirituality in this formula [...] In other words, the argument asserts that the boy Juliet is somehow more aesthetic, more central to the practice of theatre, than a female one. Tragedy and comedy lie "beyond sensual bounds", which means beyond the bounds of the female actor, who is sensual by nature of her genderxi (CASE, 1988, p. 24-25).

La autora apunta que gran parte de la crítica feminista ignora esta práctica como insidiosa para las mujeres. Esta crítica, al centrar sus análisis solamente en las lecturas de los personajes femeninos de los textos de Shakespeare, ignora la exclusión de las mujeres del palco Isabelino, y, por consiguiente, de la misoginia inherente a las prácticas de travestismo y cross-dressing de actores y personajes. Según la autora, muchas críticas feministas, aunque incluyen algún tópico dedicado al joven actor, fallan en no analizar los diversos matices que las prácticas de cross-dressing implican para las mujeres.

Para Case (1988), la mayoría de las mujeres tienden a ver solamente los puntos positivos de tales prácticas. Algunas alegando la increíble habilidad de Shakespeare de ir más allá de las rígidas convenciones de género, otras resaltando las ventajas que el travestismo trae para los actores, posibilitándoles una maturación al experimentar con personajes femeninos. De acuerdo con ella, le falta a la crítica feminista identificar la misoginia presente en la objetificación de la mujer ficcional, que funciona como mercancía que pasa de un hombre a otro dentro de una economía homoerotica. Para ella, la ficción de la mujer es necesaria para negociar el tabú de la homosexualidad.

En resumen, Sue Ellen-Case denuncia la misoginia presente no solamente en la prohibición moral de exponer la sociedad a los peligros del cuerpo de la mujer, un cuerpo "naturalmente" sexualizado. Sino que también una misoginia presente en las prácticas de cross-dressing, en la medida en que la imagen de la mujer es utilizada como mercancía para 
negociar el erotismo y la sexualidad de los actores varones. Esta última observación aún se hace presente hoy en los diversos chistes y bromas misóginas que muchos gays y hombres travestidos en drag hacen sobre la mujer, sugiriendo que las mujeres no son divertidas, ni cómicas ni graciosas. Una cultura gay que, por un lado, celebra las mujeres y la feminidad que les sirven de inspiración para su estilo de vida y performances artísticas. Pero que por otro lado denigre e insulta a las mujeres, proclamando una cierta indiferencia e independencia a las mujeres. Tal y como denuncia Valerie Solanas (1967) en su Manifiesto Scum, al decir que "no hay ninguno solo hombre rebelde en el mundo", haciendo referencia a la misoginia presente muchas veces en la cultura gay.

\section{El travestismo: cuestiones de apropiación, subversión y disidencia}

La crítica a la misoginia presente en prácticas de travestismo MTF también ha sido realizada por bell hooks (1995), en el ensayo en que debate la subversión de género operada por los travestis del documental Paris is Burning (1990), de Jennie Livinston. Así como otras feministas, bell comprende las prácticas drag MTF más como una estrategia de opresión de las mujeres, que, al ser ridiculizadas, sufren violencia misógina en términos de representación. Hooks también indaga sobre la raza, y de cómo el entrecruce de raza y género supone una doble humillación para las mujeres negras, por ejemplo. Según la autora, los hombres gays negros de la película, al travestirse de mujeres, no lo hacen tanto desde una perspectiva paródica con intenciones de desvelar el género como constructo performativo de identidad. Lo hacen más bien desde la fantasía y ansiedad por alcanzar un ideal estético de feminidad hegemónica, impuesto por la cultura blanca. Los estereotipos de belleza deseados e imitados en la película, según la autora, no son los de las mujeres negras, sino de iconos de belleza de la cultura sexista capitalista patriarcal blanca. Por esto, obedecen la demanda de la mirada y del deseo masculino del hombre blanco.

Bell hooks extiende la crítica a los procesos colonizadores de la negritud a la realizadora del documental, Jennie Livingston, argumentando que la misma asume la mirada supuestamente neutral del etnógrafo blanco occidental. Pero que, en realidad, lo que está haciendo es dirigir una cámara falocéntrica que refuerza el poder de la blanquitud en detrimento de 
la cultura negra, gay y pobre. hooks denuncia la indiferencia y frialdad con que la directora trata la muerte de Venus durante la película, diciendo que ésta solamente ha servido al espectáculo mientras estaba viva. También critica la falta de abordaje de la vida de los participantes fuera de la competición del baile. Sus vidas son retratadas como si el baile fuera un mundo aparte de fantasía que representa todo aquello que los sujetos desean y aspiran en la vida: belleza, dinero y éxito según los dictados de la cultura blanca, capitalista y patriarcal. hooks explica que, en ningún momento, la directora documenta la vida de los sujetos en comunidad, fuera del baile, sus costumbres, problemas, dificultades y conflictos en tanto comunidades de minorías vulnerables.

Las críticas de bell hooks hacen sentido desde un punto de vista de la performance como performativo que disciplina e impone los límites de la acción mimética. Sin embargo, es importante tener en cuenta las aportaciones de Judith Butler (2002) y Judith Halberstam $(1998,1999)$, que hacen una lectura diferente del documental. Una lectura que comprende el baile no desde la misoginia, sino desde el potencial crítico y subversivo de prácticas drag y queer de imitación.

Este no es un modo de apropiarse de la cultura dominante para poder permanecer subordinados a sus términos, sino que se trata de una apropiación que apunta a traspasar los términos de la dominación. Un traspaso que es en sí mismo una capacidad de actuar, un poder en el discurso y como discurso, en la actuación y como actuación, que repite para poder recrear y a veces lo logra. Pero ésta es una película que no puede conseguir ese efecto sin implicar a sus espectadores en el acto; mirar este filme significa entrar en una lógica de fetichismo que instala una relación entre la ambivalencia de esa "actuación" y la de cada uno de nosotros. Si la ambición etnográfica permite que la actuación se transforme en un fetiche exótico, del que la audiencia se aparta, la transformación en mercancía de los ideales de género heterosexuales será, en este caso, completa. Pero, si el filme establece la ambivalencia de corporizar -y no logra corporizar- aquello que uno ve, se abrirá pues una distancia entre ese llamado hegemónico a normativizar el género y su apropiación crítica (BUTLER, 2002, p. 199- 200).

Butler explica que es necesario tener en cuenta que las performances del concurso de los bailes del documental no 
pueden ser comprendidas solamente en términos misóginos, ya que representan también una forma de encarnar la propia feminidad por parte de los participantes.

Halberstam $(1998,1999)$ va a decir lo mismo al tratar de la performance drag de muchas mujeres de color, que no están preocupadas en parodiar la masculinidad, sino que asumen esta masculinidad como performance encarnada con las que se identifican. A este tipo de performance drag FTM, que corresponde a una encarnación realista de la masculinidad sin intención paródica, Halberstam llama butch realness, una de las categorías que la autora usa para explicar las particularidades del fenómeno drag King.

José Esteban Muñoz (1999), por su vez, trabaja con lo que él llama disidentificación - disidentification. Para Muñoz, la performance no siempre se traduce como una estrategia de ir en contra o enfrentamiento con la cultura hegemónica, sino que también se opera como estrategia de supervivencia y disidencia de la cultura hegemónica a partir de la negociación que se hace con ésta. Una negociación que no significa ni asimilación ni transgresión de la norma, sino más bien la creación de alternativas de ser y estar en el mundo, y nuevas formas culturales capaces de articular formas de supervivencia, militancia y activismo a través de la performance.

También había que tener en cuenta que el baile en Paris is Burning tiene por objetivo la imitación de la feminidad y masculinidad heteronormativas en lo que ellas funcionan dentro de una dinámica capitalista. En este baile, por tanto, la deconstrucción va más allá de las cuestiones de género, para también desvelar las dinámicas capitalistas que entrelazan cuestiones de poder, raza y clase.

Beatriz Preciado, en titulado "Retóricas de Género: Políticas de identidad, performance, performatividad y prótesis", resalta que la importancia del documental de Jennie Livingston es que ello no solo articula un análisis de género, sino que problematiza las políticas de identidad en un mundo capitalista. Un mundo en el cual los accesorios usados por las performers en drag revelan toda la dinámica de poder involucrada en las diferencias de raza, etnia y clase social (SEMINARIO).

Butler (2002), a pesar de considerar el riesgo que hay de que prácticas de travestismo drag refuercen la opresión de las minorías sexuales por el sistema heteronormativo, también apunta para su potencial subversivo, en la medida en que funciona como parodia de género y/o encarnación de la feminidad. Según esta autora, al imitar el género desde un cuerpo 
anatómicamente diferente de aquel supuestamente vinculado a su original, la performance paródica revela la performatividad del género. $O$ sea, el género deja de ser considerado una extensión natural del sexo anatómico, y passa a ser reconocido como performance encarnada, ritualizada históricamente a través de discursos, gestos, manierismos, accesorios escénicos, tales como vestimentas, calzados, maquillajes y peinados que dibujan estéticas de masculinidad y feminidad.

Judith Butler comprende el género como performance que, al ser históricamente repetida de forma ritualista, acaba por naturalizarse, o mejor, por adquirir la apariencia de sustancia natural, original y auténtica. Pero el género, aunque se construya dentro de una cadena de citaciones que, al ser repetidas históricamente, lo naturalizan, puede tener su significado desplazado dentro de esta cadena misma, a través de estrategias que, al evidenciarlo de forma no cotidiana - con la hipérbole, el exceso y la parodia - , desvelan su carácter performativo, o sea, construido ritualista e históricamente.

$\mathrm{Al}$ concebir el género como performance, Butler ha recibido diversas críticas por la errónea interpretación que muchos han hecho de su teoría de la performance- performatividad como algo tan voluntario como ir en un armario y cambiar de ropa, vestido o vestimenta. Pero esta es una crítica infundada. La propia Judith Butler (2002), esclarece que ella en ningún momento sugirió esto. Para la autora, el género, a pesar de construido, es un atributo performativo impuesto a los sujetos, un estatuto de identidad obligatorio que nos marca desde el nacimiento, y que por lo tanto, no es algo fácil ni de evidenciar ni de subvertir y escapar de ello. Pero sí que es posible deshacerlo y reinventarlo de forma que las diferencias sexuales, corporales y las sexualidades puedan ser más diversas, fluidas y plurales.

Catherine Connor (1994), al estudiar el travestismo de las mujeres en el escenario español, con foco en la comedia de la temprana edad moderna, defiende el potencial subversivo del travestismo de las mujeres, pero lo entiende como negociación fluida que se hace con la cultura hegemónica:

Es más bien un proceso de negociación, un baile de subversión y contención. Y después del carnaval o después de quitarse el disfraz masculino, el resultado para los contricantes - tal como para los espectadores y oyentes en el teatro - no es una vuelta al estado previo en que los dos polos de la oposición binaria regresan a su jerarquía anterior (CONNOR, 1994, p. 141). 
Siguiendo a Jonathan Dollimore (1991), Connor entiende que, después de quitarse el disfraz, el "conocimiento peligroso" experimentado durante el travestismo queda en el sistema jerárquico como repercusión desestabilizadora del sistema heteronormativo. Un conocimiento que está constante y lentamente reinscribiéndose de forma transgressiva. "La reinscripción transgresiva funciona como un recuerdo poderoso de la subversión, como lo reprimido que siempre vuelve" (CONNOR, 1994, p. 141).

Connor cree que el enfoque que muchos críticos ponen en los aspectos normativos de la comedia resulta de una actitud cartesiana, moderna y totalizante hacia la transgresión. Según la autora, estos críticos parecen relacionar la subversión con cambios inmediatos y permanentemente efectivos. "El problema es que sólo quieren ver la transgresión entendida en términos de obvios cambios de estructura y de actitud y no con respecto a lo que se reinscribe sutil y subversivamente en la pieza teatral o en la cultura" (CONNOR, 1994, p. 143-144).

Si desde el teatro, el cine y el ejemplo de teóricas como Judith Butler y bell hooks, el travestismo y mimetismo MTF, bien como la performance de las Drag Queens, se consolidaron como práctica transformista en el imaginario popular, lo mismo no se puede decir de las prácticas de travestismo y mimetismo FTM. Esto se da porque históricamente los hombres siempre tuvieron más libertad no sólo para jugar con los cambios de roles, sino también a que la cultura gay haya tenido más visibilidad y voz en la cultura popular. También es importante recordar el hecho de que la feminidad siempre estuvo vinculada con el artificio y la teatralidad, mientras la masculinidad ha sido relacionada con lo natural, la naturalidad, la no artificialidad, lo no construido, lo no performativo. De ahí que sea más fácil y/común parodiar y reírse de lo femenino que de lo masculino.

Y es que con el tiempo, a las mujeres se les permitió que se vistan no solo con faldas, vestidos y tacones, sino también con pantalones, corbatas, sandalias y men's shoes, sin que ello afecte necesariamente un planteamiento sobre su género y sexualidad. Pero este permiso - muy reciente en la historia, vale decir -, que se ha dado a las mujeres de vestirse como hombres, al mismo tiempo en que sugiere más libertad para jugar con la inversión sexual y la sexualidad; también delata el prejuicio en contra de la feminidad, que, tomada como "artificio", se pone como opuesto a lo masculino como algo "natural". La masculinidad aparece como lo natural, lo neutral, mientras la 
feminidad es sinónimo de teatralidad, exceso, artificio que se crea desde distintas tecnologías para complacer la mirada y el deseo masculino. De ahí el montón de curiosidad popular e interés académico por el tema del travestismo $M T F$, y la carencia de abordajes sobre las diversas prácticas de "masculinidad femenina" o transformación FTM, ya que éstas son consideradas de cierta forma más "común" o más próximas a una "estética natural del ser humano".

En el libro Female Masculinity, Halberstam (1988) apunta distintas formas de masculinidad sin hombres - masculinity without men. La autora nos habla de tomboys, androgynies, female husbands, tribadists, romantic friends, deportist women, rural women, worker women, butch women, y Drag Kings ${ }^{12}$.

El ejemplo de las Drag Kings merece especial atención en la payasaria, porque sus performances guardan varios elementos que se aproximan de la performance de inúmeras mujeres payaso. Tales elementos están relacionados a la corporeidad de sus performances, las masculinidades alternativas de sus gestos y voces, de sus risas y comicidades excéntricas y marginales. Las mujeres payaso, así como los Drag Kings, traen en común, en sus genealogías históricas y conceptuales, la problemática relacionada al travestismo cómico de las mujeres y que envuelve cuestiones de: aceptación, reconocimiento, passing social, subversión, encarnación de la masculinidad, visibilidad e invisibilidad en las prácticas artísticas, culturales, sociales y políticas.

\section{Consideraciones finales}

Las payasas mujeres y mujeres payaso invitan los estudios de la risa y la comicidad a repensar la construcción de la identidad y la subjetividad de las artistas en la payasaria. Partiendo de la reivindicación de género y sexualidad, la payasa invita a repensar y deconstruir la comicidad patriarcal a partir de aportaciones feministas y queer.

Las mujeres payaso, así como los Drag Kings, vienen a apoderarse del travestismo FTM en el terreno de la performance, de la risa, de la comicidad y de la parodia. Vienen a ocupar y reivindicar un espacio histórico dominado por los hombres: el travestismo, tanto a nivel social como artístico, tanto a nivel personal y del deseo, como a nivel cultural y político. Un travestismo rico en feminidades y masculinidades alternativas. Una payasaria de mujeres rica de códigos fluidos y plásticos que transitan entre las representaciones monolíticas 
de la mujer femenina y el hombre masculino, una transición que transforma esta feminidad y masculinidad hegemónicas en construcciones instables y variables.

Son muchos los interrogantes que se abren para problematizar la tipología de las mujeres payaso, desde una perspectiva de la "masculinidad femenina" y la estética política kinging. Muchos factores han de ser tomados en cuenta, como la transversalidad de las marcas de sexo, género, sexualidad, raza y etnia. Pero en general, independientemente del objetivo y estrategias usadas por comunidades blancas o de color, Halberstam (1998) apunta para lo que sería una cultura drag que, en su diversidad de manifestaciones, acaba por dinamitar la masculinidad como atributo monolítico y esencial del hombre blanco adulto. Consideramos que esta observación también es válida para las mujeres payaso.

Teniendo en cuenta lo presentado en este trabajo, terminamos este artículo planteando un par de preguntas que consideramos necesarias para la renovación del movimiento de mujeres en la payasaria:

¿En qué medida la mujer payasa hace uso de la parodia para deconstruir la feminidad como mascarada y artificio?

¿No será la "comicidad femenina" una categoría que tiende más a reforzar la feminidad de la mujer payasa - desde una perspectiva celebratoria de una identidad auténtica femenina - , que de parodiar una supuesta esencia biológica?

¿Las mujeres payaso hacen uso de la parodia para desvelar la masculinidad como atributo performativo? ¿O más bien comprenden su masculinidad desde una supuesta neutralidad y no-performatividad?

¿En qué medida las masculinidades de las mujeres payaso funcionan como mascarada, es decir, como forma de defensa personal frente a un público misógino y como forma de ocupar el espacio público de forma más segura?

Se hace necesario que las mujeres, performers y artistas de distintas disciplinas, puedan intercambiar sus experiencias y cuestionamientos, ya que el entrecruce de abordajes artísticas y teóricas son extremadamente ricos, potencialmente subversivos y transformadores de nuestra realidad social.

NOTAS

1 Las citas al largo del texto están en su versión original. Todas las traducciones han sido realizadas por la primera autora, y se encuentran como notas al final del texto.

2 "Jasmin es un niño, un niño de la calle, y al mismo tiempo, la más dulce de las niñas que ya he visto. Al llevar los dos géneros en su estado infantil, ella 
se libera de las diferenciaciones y permite construir su comicidad más allá de estas referencias."

3 "Entre muchas antologías y estudios de comediantes, las mujeres están significativamente ausentes o minimizadas. La norma no es neutral. La norma es masculina."

4 "Muchas mujeres, cuando empiezan a buscar su payaso, se enfrentan a un tipo masculino. Cosa muy normal y fácilmente explicada en un mundo aún tan dominado por los hombres y donde las referencias masculinas son tan abundantes y fuertes [...]. Al buscar su persona cómica es grande la posibilidad de que una mujer vea surgir fuerte un ser masculino, y el hecho de aceptarlo y desarrollarlo es una decisión personal, íntima y para la que no cabe crítica ni intento de interpretación o juicio."

5 Android surge primero de la necesidad de discutir la cuestión de género dentro de la esfera de actuación de payasxs en Brasil. Festivales, muestras, encuentros e incluso grupos de payasos vienen creando a veces un movimiento separatista entre hombres y mujeres, para empoderar a la mujer frente a la sociedad patriarcal en la que vivimos. Los hombres, muchas veces en las ruedas de payaso, usan la máscara para reafirmar su cultura machista. En la mayoría de los casos, ni siquiera se dan cuenta, pues incluso pequeños gestos, o simples discursos, ya están normalizados, y se convierten en comportamientos comunes dentro de las relaciones. Esto legitima el frente feminista, y hace necesaria la discusión. Pero la cultura machista también actúa de manera opresora sobre los hombres. En este caso, la discusión se amplía, siendo urgente mirarla por la lente de lo humano, donde naturaleza (sexo) y cultura (género) no son realidades separadas. [...] Androide desea estar en el entre, donde las posibilidades son plurales, proponiendo un ambiente donde no haya jerarquías ni entre sexo, ni entre sujetos culturales."

\section{6 "Híbrido terrible, un camino sin salida."}

7 "Si hubiera nacido hombre sería un clown inigualable. Desafortunadamente, sin embargo, no quiso o no consiguió encontrar un papel cómico totalmente femenino. Así, tuvo que abandonar, no sólo el papel del payaso, sino el propio oficio tout court."

8 "Algo peor que eso, sólo cuando una mujer representa uno de esos pierros. Un hombre sin sexo todavía es aceptable, pero una mujer sin sexo, nunca. [...]. Una actriz debe interpretar roles femeninos. Un actor es capaz de hacer admirablemente el papel del travestido, pudiendo encontrar, a través del sentido caricaturesco, modulaciones bastante agradables. Una mujer "transvestida" no tiene el menor significado, a menos que, en el contexto de la ficción escénica, no sea un travestismo explícito, expresado de manera evidente y cristalina. Por cierto, declaradamente: no debe haber ninguna duda de que el personaje está ejecutando un juego. Este travestimento patente fue uno de los recursos espectaculosos más utilizados en la Commedia dell'Arte. Y sólo funcionaba porque la actriz, por medio de su fascinación, de sus formas (particularmente, por la protuberancia redondeada de sus senos) y, principalmente, por su elegancia y gracia, ya había probado al público su condición femenina. Entonces, y sólo entonces, la actriz podía permitirse el travestimento."

9 Mientras que el elemento puramente ritual y/o mágico en la inversión sexual estaba presente en la literatura solo en un pequeño grado, adquirió más importancia en las festividades populares, junto con las funciones carnavalescas de burlarse y desenmascarar la verdad. Mientras que la inversión sexual en el juego literario y pictórico más frecuentemente involucraba a la mujer asumiendo el papel masculino o vestiendose como hombre, la inversión festiva involucraba más a menudo el hombre tomando el rol o vestimenta de la mujer, es decir, de la mujer rebelde. Aunque esta asimetría puede no haber existido varios siglos antes."

1o El papel raramente, si es que ha sido alguna vez, ejecutado por una mujer." 
11 La estética simplemente reemplaza la espiritualidad en esta fórmula [...] En otras palabras, el argumento afirma que el niño Julieta es de alguna manera más estético, más central para la práctica del teatro, que una mujer. La tragedia y la comedia "más allá de los límites sensuales", lo que significa más allá de los límites de la actriz, que es sensual por naturaleza de su género."

12 "Chica poco femenina, andróginas, maridos femeninos, tribadistas, amigas románticas, mujeres deportistas, mujeres rurales, mujeres obreras y trabajadoras, mujeres marimacho, y Drag Kings."

\section{Referencias}

ARISTÓTELES. Poética. Madrid: Gredos, 1999.

BERTHOLD, Margot. História mundial do teatro. São Paulo: Perspectiva, 2001.

BUTLER, Judith. Cuerpos que importan: sobre los límites materiales y discursivos del sexo. Barcelona: Paidós, 2002.

CASE, Sue-Ellen. Feminism and theatre. Houndmills: Macmillan, 1988.

CASTRO, Alice Viveiros de. O elogio da bobagem: palhaços no Brasil e no mundo. Rio de Janeiro: Editora Família Bastos, 2005.

CONNOR, Catherine. Teatralidad y resistencia: el debate sobre la mujer vestida dehombre. In: Actas de XI Congreso de la Asociación Internacional de Hispanistas, 1994, p. 139-145.

DAVIS, Natalie Zemon. Women on top: symbolic sexual inversion and political disorder in early modern Europe. In: BABCOCK, Barbara; TURNER, Victor (Ed.) Reversible World: symbolic inversion in art and society (symbol, myth and ritual). Ithaca (NY)/ London: Cornell University Press, 1978.

DOLLIMORE, Jonathan. Sexual Dissidence. Augustine to Wilde, Freud to Foucault. Oxford: Oxford University Press, 1991.

RAME, Franca. In: FO, Dario. Manual mínimo do ator. 3. ed. São Paulo: Editora SENAC, 2004.

FRAGA, Paloma [Correo electrónico] 04 out. 2015 São Paulo [para] CAMINHA, Melissa Lima. Barcelona. if. Información sobre su payasa "Android".

FRATELLINI, Annie. Destin de clown. Lyon: La Manufacture, 1989.

GAY, Jane de. Naming names: an overview of women in theatre, 1500-1900. In: GOODMAN, Lizbeth y GAY, Jane de. The Routledge reader in gender and performance. London/ New York: Routledge, 2002. p. 25-28.

HALBERSTAM, Judith. Female masculinity. Durhan/London: Durk University Press, 1998.

HALBERSTAM, Judith; VOLCANO, Del LaGrace. The drag king book. London/New York: Serpent's Tail, 1999. 
HART, Linda; PHELAN, Peggy (Ed.). Acting Out: Feminist Performances. University of Michigan Press, 1983.

HOOKS, bell. Is Paris burning? In: HOOKS, bell. Black looks: race and representation. Boston, Massachussets: South End Press, 1993.

HOROWITZ, Susan. Queens of comedy: Lucille Ball, Phyllis Diller, Carol Burnet, Joan Rivers, and the new generation of funny women. London/New York: Routledge, 2005.

JUNQUEIRA, Mariana Rabelo. Da graça ao riso: contribuições de uma palhaça sobre a palhaçaria feminina. Disertación (Maestría en en Artes Escénicas) - Centro de Letras y Artes, Universidad Federal del Estado de Rio de Janeiro, Rio de Janeiro, 2012.

NASCIMENTO, Elaine Cristina Maia.Comicidade feminina: as possibilidades de construção do cômico no trabalho de mulheres palhaças. Disertación (Maestría en en Artes Escénicas) - Escuela de Teatro, Escuela de Danza, Universidad Federal de Bahia, Salvador, 2014.

MUÑOZ, José Estebán. Disidentifications: queers of colors and the performance of politics. Minneapolis, London: University of Minnesota Press, 1999.

NOCHLIN, Linda. Why have there been no great women artists? In: VIVIAN GORNICK, Vivian; MORAN, Barbara K. Woman in sexist society: studies in power and powerlessness. New York: Basic Books, 1971.

POLLOCK, Griselda. Vision and difference: femininity, feminism and the history of art. London/New York: Routledge, 1988.

RICH, Adrienne. Compulsory Heterosexuality and Lesbian Existence. Journal of Woman's History, v. 15, n. 3, p. 11-48, 2003.

ROWE, Kathleen. The unruly woman: gender and the genres of laughter. Austin: University of Texas Press, 1995.

SEMINARIO. Texto de autoria desconocida, sobre el seminario Retóricas de Género: Políticas de identidad, performance, performatividad y prótesis. Disponible en: $<$ http://www.caladona.org/grups/uploads/2011/o2/retoricas-de-genero-politicas-de- identidad-b-preciado.pdf $>$. Acceso: 03 ago. 2015.

SOLANAS, Valerie. SCUM Manifesto. 1967. Disponible en: <http://www.iztacala.unam.mx/errancia/vi/PDFS_1/ POLIETICAS6_SCUMMANIFESTO.pdf> Acceso en: 20 mayo 2013.

TOWSEN, John H. Clowns. New York: Hawthorn Books, 1976. WITTIG, Monique. The straight mind and other essays. Boston: Beacon Press, 1992. 
. El pensamiento heterosexual y otros ensayos. Barcelona, Madrid: Egales, 2006.

Recebido em: 31/07/2017

Aceito em: 04/11/2017

\section{MELISSA LIMA CAMINHA}

melcaminha@gmail.com

Palhaça, performer, arte educadora e pesquisadora. Professora e coordenadora- Grau en Artes Escèniques (GAE), Escola Universitària ERAM / Universitat de Girona

\section{JUDIT VIDIELLA PAGÈS}

juditvidiella@gmail.com

Licenciada (1999) y Doctora (2009) en Bellas Artes por la Universidad de Barcelona (UB), mención de calidad con la tesis doctoral "Prácticas de corporización y pedagogías de contacto: una aproximación a los Estudios de Performance". Acreditada como lectora por la AQU (2009). Miembro del programa internacional de doctorado "Artes y Educación: un enfoque construccionista", coordinado por la UB, UdG y UGR. Actualmente es docente y coordinadora del Grado en Artes Escénicas (GAE) de la Escuela Universitaria ERAM - Universidad de Girona. 